Supporting Information

\title{
Kinetic Isotope Effects Quantify pH-Sensitive Water Dynamics at the Pt Electrode Interface
}

Luis Rebollar, Saad Intikhab, Joshua D. Snyder, Maureen H. Tang*

Department of Chemical and Biological Engineering, Drexel University

Philadelphia, PA 19104, USA

Corresponding Author

*Maureen H. Tang (mhtang@drexel.edu) 

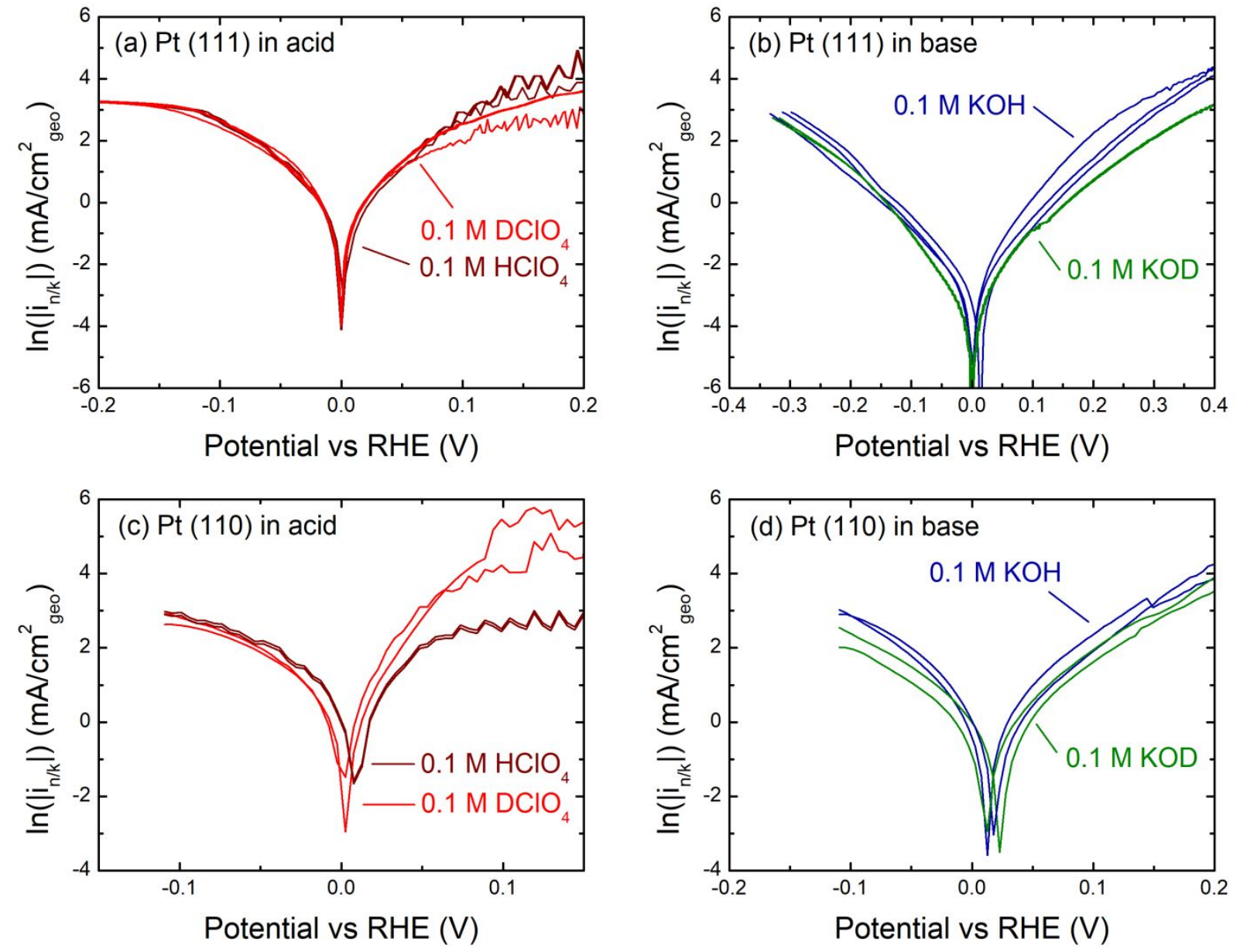

Figure S1. Reproducibility of polarization curves of (a) $\mathrm{Pt}$ (111) in $0.1 \mathrm{M} \mathrm{HClO}_{4}$ in $\mathrm{H}_{2} \mathrm{O}$ and $0.1 \mathrm{M}$ $\mathrm{DClO}_{4}$ in $\mathrm{D}_{2} \mathrm{O}$, (b) $\mathrm{Pt}(111) 0.1 \mathrm{M} \mathrm{KOH}$ in $\mathrm{H}_{2} \mathrm{O}$ and $0.1 \mathrm{M} \mathrm{KOH}$ in $\mathrm{D}_{2} \mathrm{O}$, (c) $\mathrm{Pt}$ (110) in $0.1 \mathrm{M} \mathrm{HClO}_{4}$ in $\mathrm{H}_{2} \mathrm{O}$ and $0.1 \mathrm{M} \mathrm{DClO}_{4}$ in $\mathrm{D}_{2} \mathrm{O}$, and (d) $\mathrm{Pt}(110) 0.1 \mathrm{M} \mathrm{KOH}$ in $\mathrm{H}_{2} \mathrm{O}$ and $0.1 \mathrm{M} \mathrm{KOH}$ in $\mathrm{D}_{2} \mathrm{O}$. Each polarization curve represents an independent experiment, with a clean Pt crystal in fresh electrolyte. For $\operatorname{Pt}(110)$ in acid, applying the Koutecky-Levich transform to transport-limited data for HOR does not yield meaningful kinetic information. 

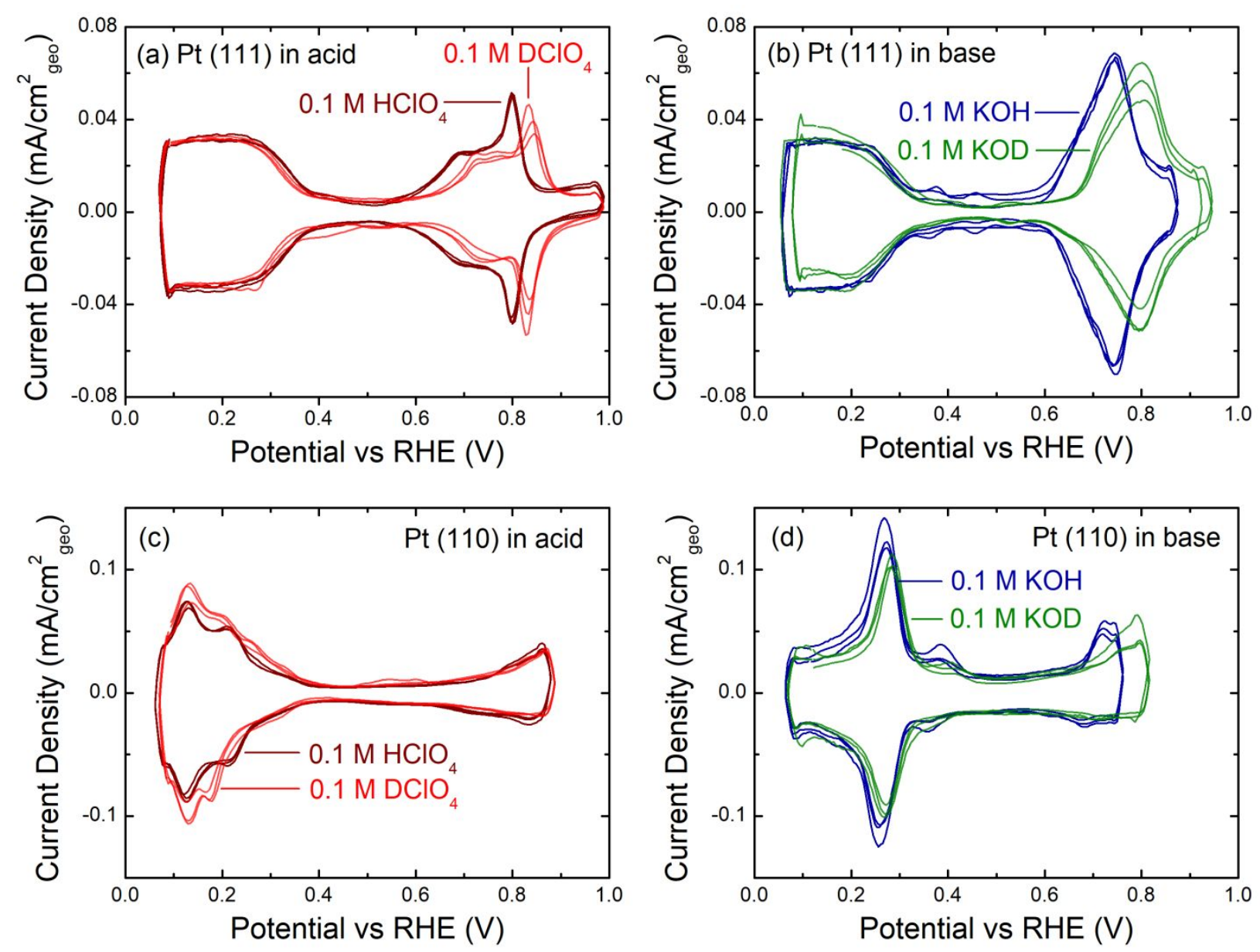

Figure S2. Reproducibility of cyclic voltammograms of (a) $\mathrm{Pt}$ (111) in $0.1 \mathrm{M} \mathrm{HClO}_{4}$ in $\mathrm{H}_{2} \mathrm{O}$ and $0.1 \mathrm{M} \mathrm{DClO}_{4}$ in $\mathrm{D}_{2} \mathrm{O}$, (b) $\mathrm{Pt}$ (111) 0.1 M KOH in $\mathrm{H}_{2} \mathrm{O}$ and $0.1 \mathrm{M} \mathrm{KOH}$ in $\mathrm{D}_{2} \mathrm{O}$, (c) Pt (110) in $0.1 \mathrm{M}$ $\mathrm{HClO}_{4}$ in $\mathrm{H}_{2} \mathrm{O}$ and $0.1 \mathrm{M} \mathrm{DClO}_{4}$ in $\mathrm{D}_{2} \mathrm{O}$, and (d) $\mathrm{Pt}(110) 0.1 \mathrm{M} \mathrm{KOH}$ in $\mathrm{H}_{2} \mathrm{O}$ and $0.1 \mathrm{M} \mathrm{KOH}$ in $\mathrm{D}_{2} \mathrm{O}$. Each cycle represents an independent experiment, with a clean Pt crystal in fresh electrolyte. 

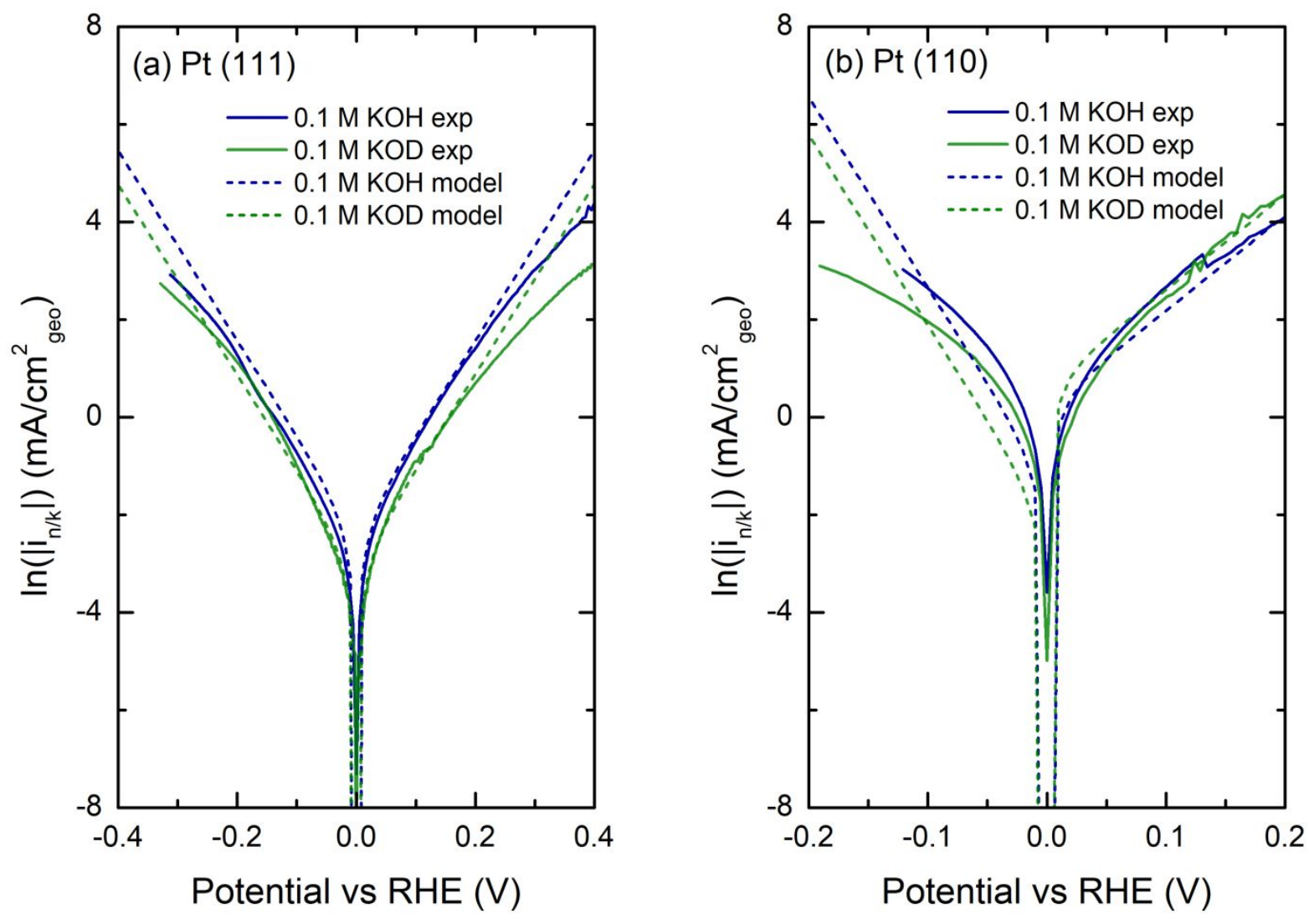

Figure S3. Example Tafel plots of experimental (solid) and simulated (dashed) current densities for (a) Pt (111) and (b) Pt (110) using a model where Volmer is the RDS and Tafel is fast. The transfer coefficient was always assumed to be $\beta=0.5$ except for HER on Pt (110), where $\beta=0.02$ was used for best fit.

\section{Tables}

Table S1. Average rate constants from fitting simulated to experimental polarization curves of $\mathrm{Pt}$ (111) and Pt (110) in alkaline electrolytes at $\pm 0.1 \mathrm{~V}$ vs. RHE assuming Volmer is the RDS and Tafel is fast.

\begin{tabular}{|l|c|c|c|c|}
\hline \multirow{2}{*}{$\begin{array}{l}\text { Electrolyte } \\
(0.1 \mathrm{M})\end{array}$} & \multicolumn{2}{|c|}{ Rate constant values $\left(\mathrm{mol} \mathrm{L}^{-1} \mathrm{~s}^{-1}\right)$ at $\pm 0.1 \mathrm{~V}$ vs. RHE } \\
\cline { 2 - 5 } & Pt (111) & HOR & HER/DER & HOR \\
\cline { 2 - 5 } & HER/DER & HOR & $3.45 \mathrm{E}+08$ & $1.97 \mathrm{E}+10$ \\
\hline $\mathrm{KOH}$ in $\mathrm{H}_{2} \mathrm{O}$ & $8.88 \mathrm{E}+05$ & $9.59 \mathrm{E}+05$ & $2.31 \mathrm{E}+08$ & $1.51 \mathrm{E}+10$ \\
\hline $\mathrm{KOH}$ in $\mathrm{D}_{2} \mathrm{O}$ & $6.78 \mathrm{E}+05$ & $5.78 \mathrm{E}+05$ & \\
\hline
\end{tabular}




\section{Prediction of KIE from Activated Complex Theory}

Activated complex theory dictates that the influence of isotopic mass on reaction kinetics can be traced to the thermodynamic activation equilibrium constant $K^{\ddagger}$, which can be computed from statistical mechanics via partition functions. Following the derivation outlined in Ref. ${ }^{1}$, Chapter 2, the expected KIE value can be expressed as:

$$
\begin{aligned}
& \frac{k_{H}}{k_{D}}=\frac{K_{H}^{\#}}{K_{D}^{\#}}=\frac{Q_{H}^{\#}}{Q_{D}^{\#}} \times \frac{Q_{D}}{Q_{H}}=\left(\frac{s_{D}^{\#}}{s_{H}^{\#}} \times \frac{s_{H}}{s_{D}}\right) \times\left(\frac{M_{H}^{\#}}{M_{D}^{\#}} \times \frac{M_{D}}{M_{H}}\right)^{3 / 2} \times\left(\frac{I_{x H}^{\#} I_{y H}^{\#} I_{z H}^{\#}}{I_{x D}^{\#} I_{y D}^{\#} I_{z D}^{\#}} \times \frac{I_{x D} I_{y D} I_{z D}}{I_{x H} I_{y H} I_{z H}}\right)^{1 / 2} \\
& \times \prod_{i}^{3 n^{*}-7 \sinh \frac{h c}{2 k T} \bar{v}_{(D)}^{\#}} \frac{h c}{\sinh \frac{h c}{2 k T} \bar{v}_{(H)}^{\#}} \prod_{i}^{3 n-6 \sinh \frac{h c}{2 k T} \bar{v}_{(D)}}
\end{aligned}
$$

Two factors which are not accounted for in Eq. (S1) are the transmission coefficient and the amount of tunneling through the potential-energy barrier. For their accurate calculation, the shape of the potential-energy surface has to be known with detail, making it difficult to account for their contributions. For most reactions at room temperature, however, the transmission coefficient does not introduce isotope effects and the tunneling contribution to the overall rate is negligible. ${ }^{2}$ These effects are also usually cancelled in the isotope effect ratio and will therefore not be considered.

One common assumption is that the molecular masses and the moments of inertia do not contribute to the KIE. This is a fair approximation for reactions involving heavy atoms (such as Pt) or for unimolecular decomposition reactions (such as hydrogen dissociation), as the substitution of hydrogen with deuterium will either have little effect on the molecular masses or moments of inertia or be cancelled in the isotope effect ratio. Further, there will be extensive cancellation between the ratio of the transition states and the reactants. Therefore, we will assume that the factors in Eq. (1) containing the molecular masses and moments of inertia are equal to unity.

Another common approximation is to assume that all but one of the vibrational contributions disappear by cancellation in calculating a KIE, where that one contributor corresponds to the stretching mode of the bond that is to be cleaved during the reaction. All other vibrational frequencies are assumed to be cancelled, either between one of the reactants and its corresponding transition state or between two isotopic species of the same kind. Under these 
assumptions, the primary factor that leads to a KIE is the change in zero-point energy (ZPE) of the breaking bond after isotopic substitution, given by $\triangle Z P E=\frac{1}{2} h\left(v_{H}-v_{D}\right)$. From Eq. (S1), the expression for the expected KIE can be simplified to Eq. (S2).

$$
\frac{k_{H}}{k_{D}}=\exp \left\{\frac{h c}{2 k T}\left(\bar{v}_{(H)}-\bar{v}_{(D)}\right)\right\}
$$

If the stretching frequency of one of the isotopic bonds is not known, we can refer back to the classical harmonic oscillator to calculate one from the other by means of the reduced masses of the systems, as shown by Eq. (S3).

$$
\bar{v}_{\bar{v}(H)}=\left(\frac{\mu_{(H)}}{\mu_{(D)}}\right)^{1 / 2}
$$

Herein, we focus on a model for HER on Pt (111). Pt (110) is not considered because Pt (110) in acid is too fast to measure KIEs experimentally (Fig. 1c), which prevents a direct comparison of the importance of interfacial water in acid vs. base. Further, a model for HOR on $\mathrm{Pt}$ (111) is not considered because in our experiments, the RDS is always the cleavage of the $\mathrm{Pt}-\mathrm{H}$ bond, so there is no primary KIE for this case. Thus, the reaction model we consider is that of a single water molecule next to a Pt (111) surface during HER, the RDS of which is well-known to be the Volmer step in alkaline media. ${ }^{3-7}$ If we consider the Volmer step to be limited by the dissociation of hydrogen from an interfacial water molecule prior to its adsorption onto Pt, then the KIE will be given by the change in the ZPE of the $\mathrm{O}-\mathrm{H}$ bond. The stretching frequency of the $\mathrm{O}-\mathrm{H}$ bond in water is $\bar{v}_{(H)}=3650 \mathrm{~cm}^{-1,8}$ giving an estimated frequency of the $\mathrm{O}-\mathrm{D}$ bond to be $\bar{v}_{(D)}=2580 \mathrm{~cm}^{-1}$. Eq. (2) then gives an expected KIE value of 13.2 .

The discrepancy between the calculated and the measured KIE values suggests that this model of the alkaline Volmer step which consists of the dissociation of a single water molecule incomplete and that other reaction phenomena need to be considered, such as the hydrogen bonding network and the interfacial electric field. A major assumption made in these calculations is that the stretching mode of the cleaving bond is the primary contributor to the KIE, and that all other vibrational contributions are constants and therefore cancelled in the isotope effect ratio. However, the hydrogen bonding network in particular may suppress the vibrational frequencies of the $\mathrm{O}-\mathrm{H}$ bonds before passing to the transition state. Hydrogen bonding in water is known to lengthen the $\mathrm{O}-\mathrm{H}$ bond and decrease its stretching frequency. ${ }^{8,9}$ Therefore, it is likely that when breaking away from the hydrogen bonding network in passing to the transition state, other 
stretching and bending frequencies of the dissociating water molecule, will increase considerably, meaning that these vibrational contributions will not disappear by cancellation. An increase in the ZPEs of the bonds in the transition state will lead to a weaker isotope effect, which may explain the discrepancy between the calculated and the experimentally measured KIE values. Therefore, while Eq. (S2) is suitable for many applications, its inability even to approximate the measurements here demonstrates the magnitude of changes to stretching frequencies caused by the electrochemical setting, including hydrogen bonding, spectator ions, and strong electric fields. ${ }^{1,9}$

\section{List of Symbols}

\begin{tabular}{|c|c|}
\hline Symbol & Denotation \\
\hline $\mathrm{c}$ & Speed of light, $\mathrm{m} \mathrm{s}^{-1}$ \\
\hline $\mathrm{h}$ & Planck constant, $\mathrm{m}^{2} \mathrm{~kg} \mathrm{~s}^{-1}$ \\
\hline $\mathrm{i}_{\mathrm{k}}$ & Kinetic current density, $\mathrm{mA} \mathrm{cm}{ }^{-2}$ \\
\hline $\mathrm{i}_{\mathrm{n}}$ & Current density, $\mathrm{mA} \mathrm{cm}^{-2}$ \\
\hline $\mathrm{I}_{\mathrm{xy}}, \mathrm{I}_{\mathrm{xz}}, \mathrm{I}_{\mathrm{yz}}$ & Moments of inertia of reactant in $x y, x z$, and yz planes \\
\hline $\mathrm{I}_{\mathrm{xy}}^{\#}, \mathrm{I}_{\mathrm{xz}}^{\#}, \mathrm{I}_{\mathrm{yz}}^{\#}$ & Moments of inertia of transition state in $\mathrm{xy}, \mathrm{xz}$, and yz planes \\
\hline $\mathrm{k}$ & Boltzmann constant, $\mathrm{m}^{2} \mathrm{~kg} \mathrm{~s}^{-2} \mathrm{~K}^{-1}$ \\
\hline $\mathrm{k}_{\mathrm{H}}, \mathrm{k}_{\mathrm{D}}$ & Rate constant (for H and D systems, respectively), $\mathrm{s}^{-1}$ \\
\hline $\mathrm{K}_{\mathrm{H}}, \mathrm{K}_{\mathrm{D}}$ & Equilibrium constant (for $\mathrm{H}$ and $\mathrm{D}$ systems, respectively) \\
\hline $\mathrm{K}_{\mathrm{H}}^{\#}, \mathrm{~K}_{\mathrm{D}}^{\#}$ & Transition state equilibrium constant \\
\hline $\mathrm{M}_{\mathrm{H}}, \mathrm{M}_{\mathrm{D}}$ & Molecular mass of reactants \\
\hline $\mathrm{M}_{\mathrm{H}}^{\#}, \mathrm{M}_{\mathrm{D}}^{\#}$ & Molecular mass of transition state \\
\hline $\mathrm{Q}_{\mathrm{H}}, \mathrm{Q}_{\mathrm{D}}$ & Partition function of reactants \\
\hline $\mathrm{Q}^{\#}{ }_{\mathrm{H}}, \mathrm{Q}^{\#} \mathrm{D}$ & Partition function of transition state \\
\hline $\mathrm{R}$ & Gas constant, $\mathrm{J} \mathrm{mol}^{-1} \mathrm{~K}^{-1}$ \\
\hline $\mathrm{r}$ & Reaction rate, $\mathrm{mol} \mathrm{cm}^{-2} \mathrm{~s}^{-1}$ \\
\hline $\mathrm{S}_{\mathrm{H}}, \mathrm{S}_{\mathrm{D}}$ & Symmetry number \\
\hline $\mathrm{s}_{\mathrm{H}}^{\#}, \mathrm{~s}_{\mathrm{D}}^{\#}$ & Transition state symmetry number \\
\hline $\mathrm{T}$ & Temperature, $\mathrm{K}$ \\
\hline$\Delta \mathrm{G}^{\circ}$ & Change in free energy of adsorption, $\mathrm{eV}$ \\
\hline$\beta$ & Transfer coefficient \\
\hline
\end{tabular}




\begin{tabular}{|l|l|}
\hline$\eta$ & Diffusion overpotential \\
\hline$\mu$ & Reduced mass \\
\hline $\bar{v}$ & Wavenumber, $\mathrm{cm}^{-1}$ or $^{-1}$ \\
\hline
\end{tabular}

\section{References}

1. Gaylord, N. G.; Eliel, E. L.; Isotope effects on reaction rates. Lars Melander. Ronald Press, New York, 1960. vi + 181 pp. J Polym Sci. 1961. doi:10.1002/pol.1961.1204915241

2. Hirschfelder, J. O.; Wigner, E.; Some quantum-mechanical considerations in the theory of reactions involving an activation energy. J Chem Phys. 1939. doi:10.1063/1.1750500

3. Intikhab, S.; Rebollar, L.; Fu, X.; et al.; Exploiting dynamic water structure and structural sensitivity for nanoscale electrocatalyst design. Nano Energy. 2019; 64:103963. doi:10.1016/j.nanoen.2019.103963

4. Li, J.; Ghoshal, S.; Bates, M. K.; et al.; Experimental Proof of the Bifunctional Mechanism for the Hydrogen Oxidation in Alkaline Media. Angew Chemie Int Ed. 2017; 56(49):15594-15598. doi:10.1002/anie.201708484

5. Liu, E.; Li, J.; Jiao, L.; et. al.; Unifying the Hydrogen Evolution and Oxidation Reactions Kinetics in Base by Identifying the Catalytic Roles of Hydroxyl-Water-Cation Adducts. $J$ Am Chem Soc. 2019. doi:10.1021/jacs.8b13228

6. Bates, M. K.; Jia, Q.; Ramaswamy, N.; Allen, R. J.; Mukerjee, S.; Composite Ni/NiOCr2O3 catalyst for alkaline hydrogen evolution reaction. J Phys Chem C. 2015. doi:10.1021/jp512311c

7. Yang, X.; Nash. J.; Oliveira, N.; Yan, Y.; Xu, B.; Understanding the pH Dependence of Underpotential Deposited Hydrogen on Platinum. Angew Chemie. 2019. doi:10.1002/ange.201909697

8. Qian, W.; Krimm, S.; Vibrational spectroscopy of hydrogen bonding: Origin of the different behavior of the C-H..O hydrogen bond. J Phys Chem A. 2002. doi:10.1021/jp020438g

9. Ibers, J. A.; Hydrogen bonding (Vinogradov, Serge N.; Linnell, Robert H.). J Chem Educ. 1972. doi:10.1021/ed049pa102.2 
